\title{
NOD2: a potential target for regulating liver injury
}

\author{
Mathilde Body-Malapel ${ }^{1,2,3,14}$, Sébastien Dharancy ${ }^{1,2,3,14}$, Dominique Berrebi ${ }^{4}$, Alexandre Louvet ${ }^{1,2,3}$, \\ Jean-Pierre Hugot ${ }^{5}$, Dana J Philpott ${ }^{6}$, Marco Giovannini ${ }^{7}$, Fabrice Chareyre ${ }^{7}$, Gilles Pages ${ }^{8}$, Emilie Gantier ${ }^{1,2,3}$, \\ Stephen E Girardin ${ }^{9}$, Irène Garcia ${ }^{10}$, Sylvie Hudault ${ }^{11}$, Filoména Conti ${ }^{12}$, Philippe J Sansonetti ${ }^{13}$, \\ Mathias Chamaillard ${ }^{1,2,3}$, Pierre Desreumaux ${ }^{1,2,3}$, Laurent Dubuquoy ${ }^{1,2,3}$ and Philippe Mathurin ${ }^{1,2,3}$
}

The recent discovery of bacterial receptors such as NOD2 that contribute to crosstalk between innate and adaptive immune systems in the digestive tract constitutes an important challenge in our understanding of liver injury mechanisms. The present study focuses on NOD2 functions during liver injury. NOD2, TNF- $\alpha$ and IFN- $\gamma$ mRNA were quantified using real-time PCR in liver samples from patients and mice with liver injury. We evaluated the susceptibility of concanavalin A (ConA) challenge in NOD2-deficient mice ( $\mathrm{Nod}_{2}{ }^{-1}$ ) compared to wild-type littermates. We tested the effect of muramyl dipeptide (MDP), the specific activator of NOD2, on ConA-induced liver injury in C57BL/6 mice. We studied the cellular distribution and the role of NOD2 in immune cells and hepatocytes. We demonstrated that NOD2, TNF- $\alpha$ and IFN- $\gamma$ were upregulated during liver injury in mice and humans. Nod $2^{-/-}$mice were resistant to ConA-induced hepatitis compared to their wild-type littermates, through reduced IFN- $\gamma$ production by immune cells. Conversely, administration of MDP exacerbated ConA-induced liver injury. MDP was a strong inducer of IFN- $\gamma$ in freshly isolated human PBMC, splenocytes and hepatocytes. Our study supports the hypothesis that NOD2 contributes to liver injury via a regulatory mechanism affecting immune cells infiltrating the liver and hepatocytes. Taken together, our results indicate that NOD2 may represent a new therapeutic target in liver diseases.

Laboratory Investigation (2008) 88, 318-327; doi:10.1038/labinvest.3700716; published online 28 January 2008

KEYWORDS: inflammation; innate immunity; liver; NOD2; lymphocyte

Liver injury is associated with elevated bacterial translocation related to an intestinal phenomenon designated 'leaky gut'. The latter contributes to a rise in bacterial cell wall products, also called pathogen-associated molecular patterns (PAMP), in portal tracts. ${ }^{1}$ PAMP may enhance inflammatory processes within the liver through their interaction with pathogen recognition receptors. It has recently been suggested that peptidoglycan, a cell wall product common to both Grampositive and Gram-negative bacteria, may be an important inducer of the proinflammatory process in the digestive tract. $^{2,3}$

NOD2 is a new cytosolic pathogen recognition receptors, which functions at the crossroads of innate and adaptive immune responses. It has been reported to contribute to the proinflammatory process of intestinal disorders such as Crohn's disease. ${ }^{4}$ NOD2, encoded by the CARD15 gene, is expressed in immune cells such as monocytes/macrophages, $\mathrm{T}$ lymphocytes, granulocytes, dendritic cells and also in colon epithelial cells. ${ }^{5-7}$ This receptor is the specific sensor for muramyl dipeptide (MDP), a frequently described immunostimulatory peptidoglycan motif common to all bacteria. ${ }^{3,8,9}$ MDP recognition by NOD2 leads to activation of nuclear factor- $\kappa \mathrm{B}$ and induces proinflammatory cytokine production by immune cells through a Rip-like interactive clarp kinase-dependent signaling pathway. ${ }^{6,10}$ Interestingly, TNF- $\alpha$ can also induce NOD2 expression via a consensus site

\footnotetext{
1'INSERM U795, Lille, France; ${ }^{2}$ Université Lille 2, Lille, France; ${ }^{3} \mathrm{CHRU}$ Lille, Hôpital Huriez, Service des Maladies de l'Appareil digestif et de la Nutrition, Lille, France; ${ }^{4}$ Service d'Anatomie et de Cytologie pathologiques, AP-HP, France et Equipe d'Accueil 3102, Université Paris VII, Hôpital Robert Debré, Paris, France; ${ }^{5}$ Unité INSERM U843, Hôpital Robert Debré, AP-HP, Paris, France; ${ }^{6}$ Department of Immunology, University of Toronto, Toronto, Ontario, Canada; ${ }^{7}$ INSERM U674, Génomique fonctionnelle des Tumeurs solides, Fondation Jean Dausset-CEPH, Paris, France; ${ }^{8}$ CNRS, Unité mixte de Recherche 6543 , Faculté de Sciences, Université de Sophia Antipolis, Nice, France; ${ }^{9}$ Department of Laboratory Medicine and Pathobiology, University of Toronto, Toronto, Ontario, Canada; ${ }^{10}$ Department of Pathology and Immunology, University of Geneva, Geneva, Switzerland; ${ }^{11}$ INSERM U510 Pathogens and functions of polarized epithelial cells, Faculty of Pharmacy, University Paris XI, Châtenay-Malabry, France; ${ }^{12}$ Laboratoire de Biologie cellulaire, Université Paris V, Service de Chirurgie, Hôpital Cochin, Paris, France and ${ }^{13}$ INSERM U786 Pathogénie microbienne moléculaire, Institut Pasteur, Paris, France

Correspondence: Dr S Dharancy, MD, PhD, Service des Maladies de l'Appareil digestif et de la Nutrition, Hôpital Huriez, rue Michel Polonowski, CHU, Lille 59037, France. E-mail: s6@chru-lille.fr

${ }^{14}$ These authors contributed equally to this work.

Received 7 September 2007; revised 6 November 2007; accepted 20 November 2007
} 
for NF- $\kappa \mathrm{B}$ contained in its promoter. ${ }^{11}$ Since NOD2 regulates the inflammatory process in the digestive tract, we hypothesized that it may also play a pivotal role in regulation of liver injury.

In the present study, we demonstrate for the first time that: (1) NOD2 expression is upregulated during liver injury in mice and humans; (2) NOD2-deficient mice $\left(\mathrm{Nod}_{2}^{-l-}\right.$ ) are resistant to concanavalin A (ConA)-induced hepatitis compared to their wild-type littermates, through reduced IFN- $\gamma$ production by immune cells; (3) administration of MDP, the specific activator of NOD2, exacerbates ConA-induced liver injury; and (4) MDP is a potent inducer of cytokines in freshly isolated peripheral blood mononuclear cells (PBMC), splenocytes and hepatocytes. Taken together, these results strongly indicate that NOD2 is involved in regulation of liver injury and could represent a new therapeutic target in liver diseases.

\section{MATERIALS AND METHODS Tissue Samples and Cells}

In vitro, NOD2 expression was evaluated in isolated human hepatocytes and PBMC. NOD2 regulation in mice was evaluated in both ConA $(10 \mathrm{mg} / \mathrm{kg})$ - and LPS $(10 \mu \mathrm{g})$-induced liver injuries. Livers were removed 2, 4, 8, 12 and $24 \mathrm{~h}$ after retro-orbital ConA administration, and 1, 2, 4, 6, 12 and $24 \mathrm{~h}$ after intraperitoneal LPS injection. Human livers were obtained from control patients undergoing tumor resection without liver disease $(n=15)$. Inflamed livers were taken from patients with autoimmune hepatitis $(n=5)$. Hepatocytes were isolated from control livers of patients using the perfusion/collagenase method. ${ }^{12}$ All patients had given informed consent and the project was approved by the ethical committee of Lille Hospital.

\section{Detection and Quantification of NOD2 and Cytokine mRNA Levels}

Real-time PCR analyses were performed for quantification of NOD2, TNF- $\alpha$, IFN- $\gamma$ mRNA expression (Table 1). TATA box-binding protein and $\beta$-actin were used as housekeeping genes. ${ }^{13}$ Sequence-specific PCR primers were designed using primer Express Software version 1.5 (Applied Biosystems, Foster City, CA, USA; see Table 1 for details). One microgram of RNA was retro-transcribed using Superscript ${ }^{\circledR}$ (Invitrogen, Cergy-Pontoise, France) following the manufacturer's recommendations. Quantification of cDNA was performed using ABI Prism 7000 (Applied Biosystems, Foster City, CA, USA). Mouse and human NOD2 PCR products were sequenced using ABI Prism 377 XL (Applied Biosystems, Foster City, CA, USA) and were compared to the reference NM_145857 and NM_022162.

\section{NOD2 and CD68 Staining by Immunofluorescence Microscopy}

For NOD2 immunostaining, we used three different antibodies (one monoclonal and two polyclonal) directed against
Table 1 Human and mouse primer sequences for real-time PCR

\begin{tabular}{|c|c|}
\hline Human IFN- $\gamma \mathrm{F}$ & $5^{\prime}$-CCAACGCAAAGCAATACATGA-3' \\
\hline Human IFN- $\gamma \mathrm{R}$ & 5'-CCTITTCGCTTCCCTGTITA-3' \\
\hline Human Nod2 F & $5^{\prime}$-CGG CGT TCC TCA GGA AGT AC-3' \\
\hline Human Nod2 R & $5^{\prime}$-ACC CCG GGC TCA TGA TG-3' \\
\hline Human TBP F & $5^{\prime}$-CACGAACCACGGCACTGATT-3' \\
\hline Human TBP $R$ & $5^{\prime}$-TाTCTTGCTGCTGCCAGTCTGGAC-3' \\
\hline Human TNF- $\alpha$ F & $5^{\prime}$-GGA GAA GGG TGA CCG ACT CA-3' \\
\hline Human TNF- $\alpha$ R & $5^{\prime}$-CTG CCC AGA CTC GGC AA-3' \\
\hline Human $\beta$-actin $\mathrm{F}$ & 5'-TCA CCC ACA CTG TGC CCA TCT ACG-3' \\
\hline Human $\beta$-actin $\mathrm{R}$ & $5^{\prime}$-CAG CGG AAC CGC TCA TTG CCA ATG-3' \\
\hline Mouse IFN- $\gamma \mathrm{F}$ & 5'-TCA AGT GGC ATA GAT GTG GAA GAA-3' \\
\hline Mouse IFN- $\gamma \mathrm{R}$ & 5'-TGG CTC TGC AGG ATT TTC ATG-3' \\
\hline Mouse Nod2 F & $5^{\prime}$-CCT GGT ACG TGC CCA AAG TAG-3' \\
\hline Mouse Nod2 R & $5^{\prime}$-GCC AAG TAG AAA GCG GCA AA-3' \\
\hline Mouse TNF- $\alpha \mathrm{F}$ & 5'-CAT CTT CTC AAA ATT CGA GTG ACA A-3' \\
\hline Mouse TNF- $\alpha$ R & $5^{\prime}$-TGG GAG TAG ACA AGG TAC AAC CC-3' \\
\hline Mouse $\beta$-actin $\mathrm{F}$ & $5^{\prime}$-AGA GGG AAA TCG TGC GTG AC-3' \\
\hline Mouse $\beta$-actin $\mathrm{R}$ & $5^{\prime}$-CAA TAG TGA TGA CCT GGC CGT-3' \\
\hline
\end{tabular}

$F$, forward; $R$, reverse.

either the leucine-rich repeats (LRR) region ${ }^{14,15}$ or the caspase recruitment domain of NOD2 (Cayman Chemical, Ann Arbor, MI, USA). The three antibodies gave similar results. NOD2 immunostainings presented in the different figures were performed with an antibody from Cayman Chemical. Livers were fixed in paraformaldehyde (PFA) $4 \%$ and embedded in paraffin. Four-micrometer-thick sections were exposed to primary antibodies directed against NOD2 (dilution 1:50) and then to Alexa-488-conjugated secondary antibody for $1 \mathrm{~h}$ (dilution 1:100). Negative controls were incubated with rabbit serum instead of specific antibody, or with specific antibody preincubated with an excess of recombinant NOD2-LRR protein. Immunofluorescence was revealed under a fluorescence microscope (Leica, Bensheim, Germany). Immune mononuclear cells were identified with CD68. NOD2-CD68 double-staining was performed by adding one step to the protocol of NOD2 staining described above and analyzed with confocal microscopy.

\section{Study of the Susceptibility of Nod2-Deficient Mice to ConA-Induced Hepatitis}

C57BL/6 background Nod2 knockout mice $\left(\mathrm{Nod}_{2}{ }^{-1-}\right.$ ) were generated in the laboratory of $\mathrm{M}$ Giovannini. ${ }^{16}$ The first Nod 2 coding exon was deleted, resulting in a null Nod2 allele. Germline-transmitting chimeras were crossed with C57BL/6 mice to generate Nod2 ${ }^{+/-}$mice. After ten backcrosses with C57BL/6 mice, Nod2 ${ }^{+/-}$mice were intercrossed to generate 
Nod $2^{-1-}$ mice. Nod2 $2^{-1-}$ mice were macroscopically and histologically indistinguishable from controls and showed no sign of liver pathology. Eight-week-old Nod2 $2^{+1+}(n=24)$ and $\operatorname{Nod} 2^{-I-}$ mice $(n=27)$ were injected with $10 \mathrm{mg} / \mathrm{kg}$ of
ConA in three independent experiments. Blood was collected and livers were harvested 8 and $24 \mathrm{~h}$ after ConA injection. A ConA-induced hepatitis model was selected because it is characterized by high levels of inflammatory cytokines a
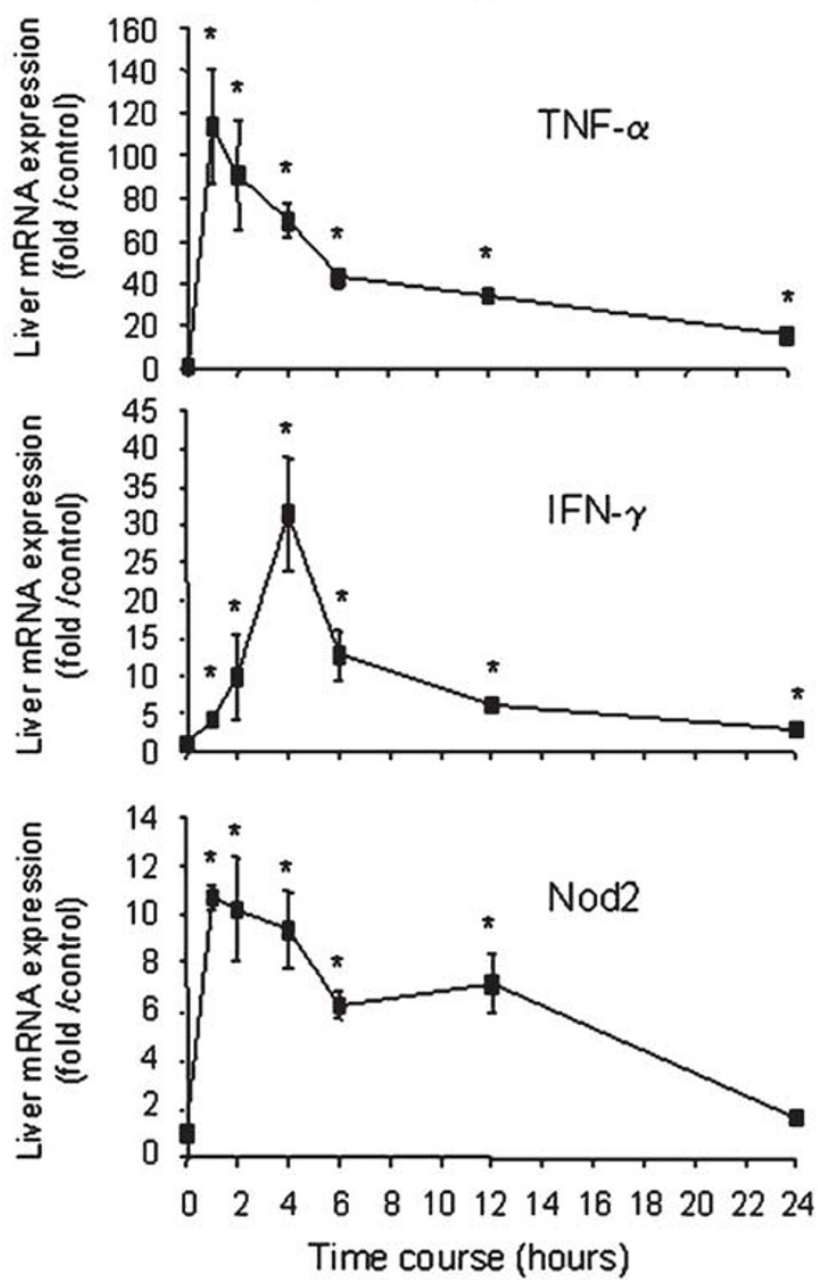

b
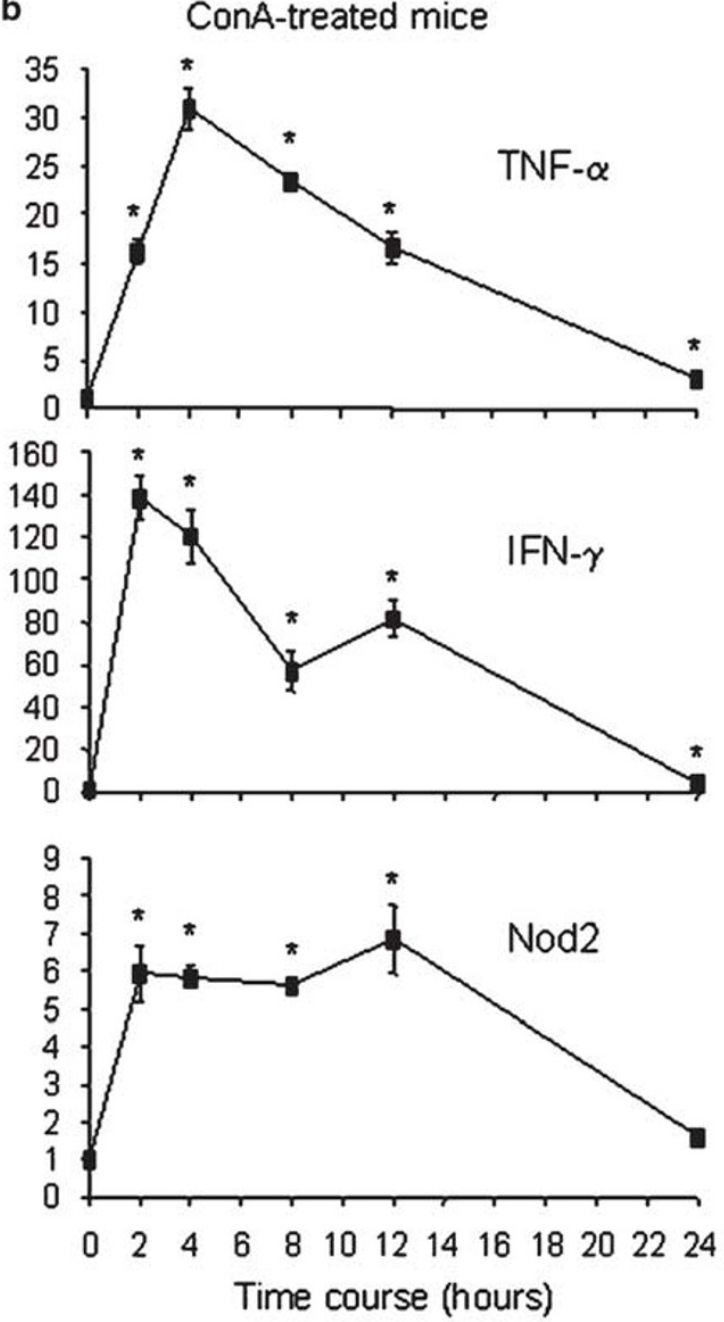

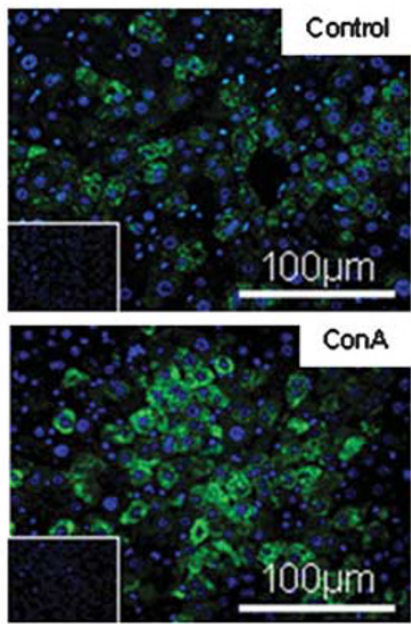

d

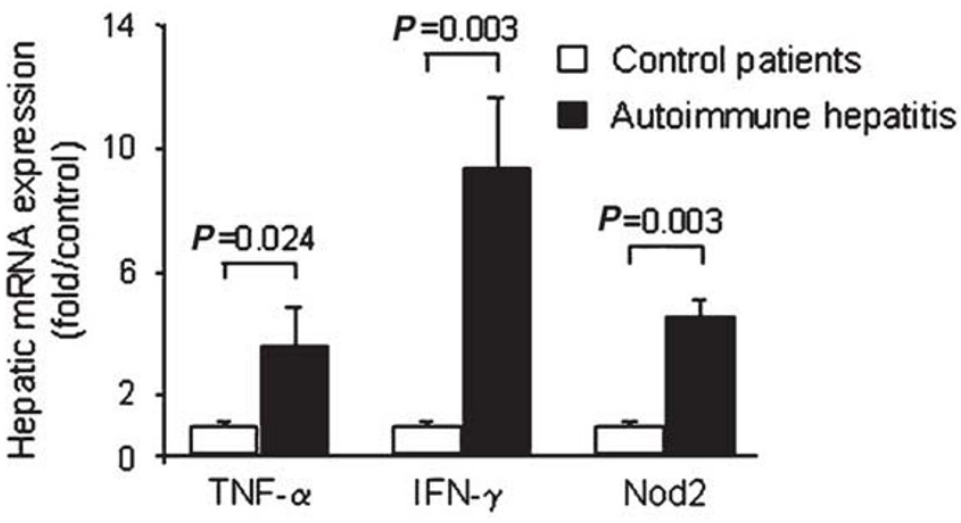


(TNF- $\alpha$ and IFN- $\gamma$ ) and is the closest model for lymphocytemediated liver injury, such as autoimmune hepatitis in humans. Aspartate aminotransferase (AST), alanine transaminase (ALT) and lactate dehydrogenase (LDH) were measured in the sera of mice using the standard photometric method

a

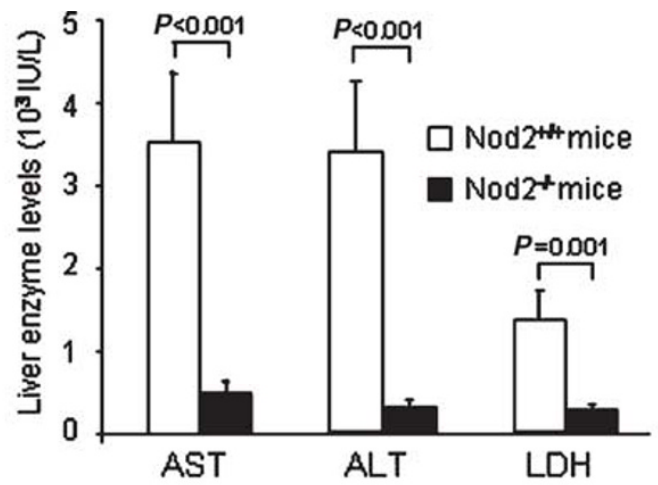

b

b Necrosis
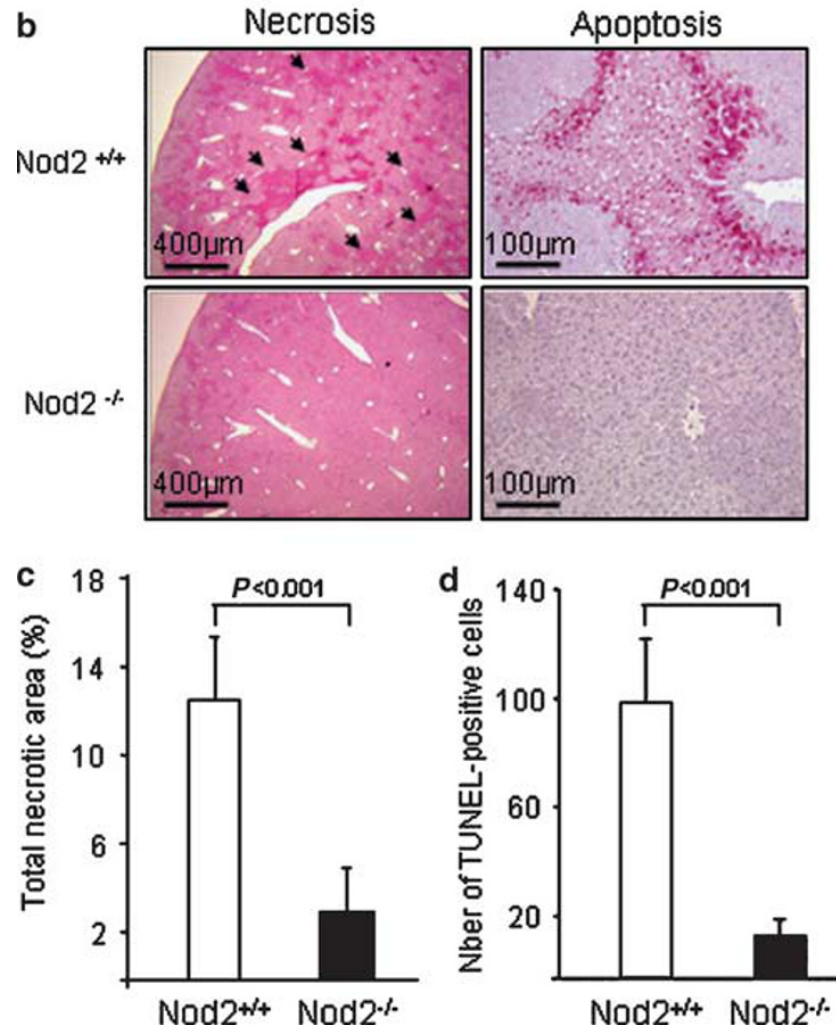

(Hitashi 747 analyzer). NIH Image 1.61 (http://rsb.info.nih.gov/ij/) was used to calculate the local area of hepatocyte necrosis from video micrograph TIFF files. Cells undergoing apoptosis were identified by enzymatic labelling of DNAstrand breaks using a terminal transferase dUTP nick end labelling assay (TUNEL assay, Roche Diagnostics, Meylan, France). The mean \pm s.e.m. number of TUNEL-positive hepatocytes was determined by manual counting of eight fields (magnification $\times 400)$ per liver $(200$ cells per field) in eight wild-type and eight Nod2 $2^{-1-}$ mice. Liver sections were incubated overnight with a primary rat monoclonal antibody directed against IFN- $\gamma$ (dilution 1:100, Interchim, Montluçon, France). Negative controls consisted of omission of the first antibody and use of an irrelevant antibody. Eight hours after ConA injection, NF- $\kappa \mathrm{B}$ activity was assessed by evaluation of $\mathrm{I} \kappa \mathrm{B} \alpha$ degradation using western blot.

\section{Role of MDP in ConA-Induced Liver Injury}

Muramyl dipeptide, the specific activator of Nod2, has been purchased from Sigma Chemical (Sigma-Aldrich Chimie, Lyon, France). The MDP purity has been tested by HPLC ( $98 \%$ of purity). The specificity of MDP for Nod2 has been previously reported by Girardin and coll. ${ }^{9}$ Eight-week-old C57BL $/ 6$ mice were injected with $10 \mathrm{mg} / \mathrm{kg}$ of ConA. Just after ConA injection, eight mice received an i.p. injection of MDP $(100 \mathrm{mg} / \mathrm{kg})$ and eight mice received saline instead of MDP in two independent experiments. As controls, five mice

Figure 2 Nod2 ${ }^{-1-}$ mice are protected from ConA-induced hepatitis. Nod2 $2^{-1-}$ mice $(n=27)$ and Nod2 ${ }^{+1+}$ mice $(n=24)$ were injected with $10 \mathrm{mg} / \mathrm{kg}$ of ConA. (a) Nod2 $2^{-1-}$ mice showed a decrease in their serum liver enzyme levels as compared with Nod2 $2^{+1+}$ mice. (b) Representative H\&E (left panel) and TUNEL staining (right panel) of liver sections from Nod2 ${ }^{+1+}$ (upper panel) and $\mathrm{Nod}^{-/-}$mice (lower panel) challenged with ConA. Histological analysis showed necrosis (arrows) and infiltration of mononuclear and polymorphonuclear cells in $\mathrm{Nod}^{+/+}$mice, whereas moderate morphological alterations were observed in livers of Nod2 $2^{-1-}$ mice (magnification $\times 25$ ). A substantial number of apoptotic cells (red nuclei) were identified by TUNEL staining in Nod2 $2^{+/+}$mice, whereas apoptotic changes remained weak in Nod2 $2^{-1-}$ mice. (c) The total necrotic area was significantly reduced in $\mathrm{Nod} 2^{-1-}$ mice compared with $\mathrm{Nod} 2^{+1+}$ mice. (d) Quantification of TUNEL-positive cells in eight consecutive fields showed a decrease in hepatocyte apoptosis in Nod2 ${ }^{-1-}$ compared with $\mathrm{Nod} 2^{+1+}$ livers. Results are expressed as mean \pm s.e.m. Statistical significances are indicated.

Figure 1 Hepatic expression of NOD2 during liver injury. (a) LPS-mediated liver injury in mice. C57BL/6 mice received either physiological serum (controls) or LPS $(10 \mu \mathrm{g})$ i.p. and were killed 1, 2, 4, 6, 12 and $24 \mathrm{~h}$ after injection (four mice per group). Liver mRNAs of TNF- $\alpha$ (higher panel), IFN- $\gamma$ (middle panel) and NOD2 (lower panel) were quantified using real-time PCR. Results are expressed as fold induction compared to controls and represented as mean \pm s.d. Significant differences are indicated by ${ }^{*}$. (b) ConA-mediated liver injury in mice. C57BL/6 mice received either physiological serum (controls) or ConA $(10 \mathrm{mg} / \mathrm{kg}$ ) by retro-orbital injection and were killed 2, 4, 8, 12 and $24 \mathrm{~h}$ after injection (four mice per group). Liver mRNAs of TNF- $\alpha$ (higher panel), IFN- $\gamma$ (middle panel) and NOD2 (lower panel) were quantified using real-time PCR. Results are expressed as fold induction compared with controls and represented as mean \pm s.d. Significant differences are indicated by ${ }^{*}$. (c) NOD2 immunofluorescent staining appeared less intense in control liver compared with inflamed liver (magnification $\times 200$ ). Negative controls were seen in insert in the lower left-hand corner. (d) Hepatic expression of NOD2 and inflammatory cytokine mRNA levels in human autoimmune hepatitis. TNF- $\alpha$, IFN- $\gamma$ and NOD2 mRNA levels were highly induced in inflamed liver compared with control patients ( $P=0.024$ for TNF- $\alpha$ and $P=0.003$ for IFN $-\gamma$ and NOD2). Results are expressed as mean \pm s.e.m. Statistical significances are indicated. 

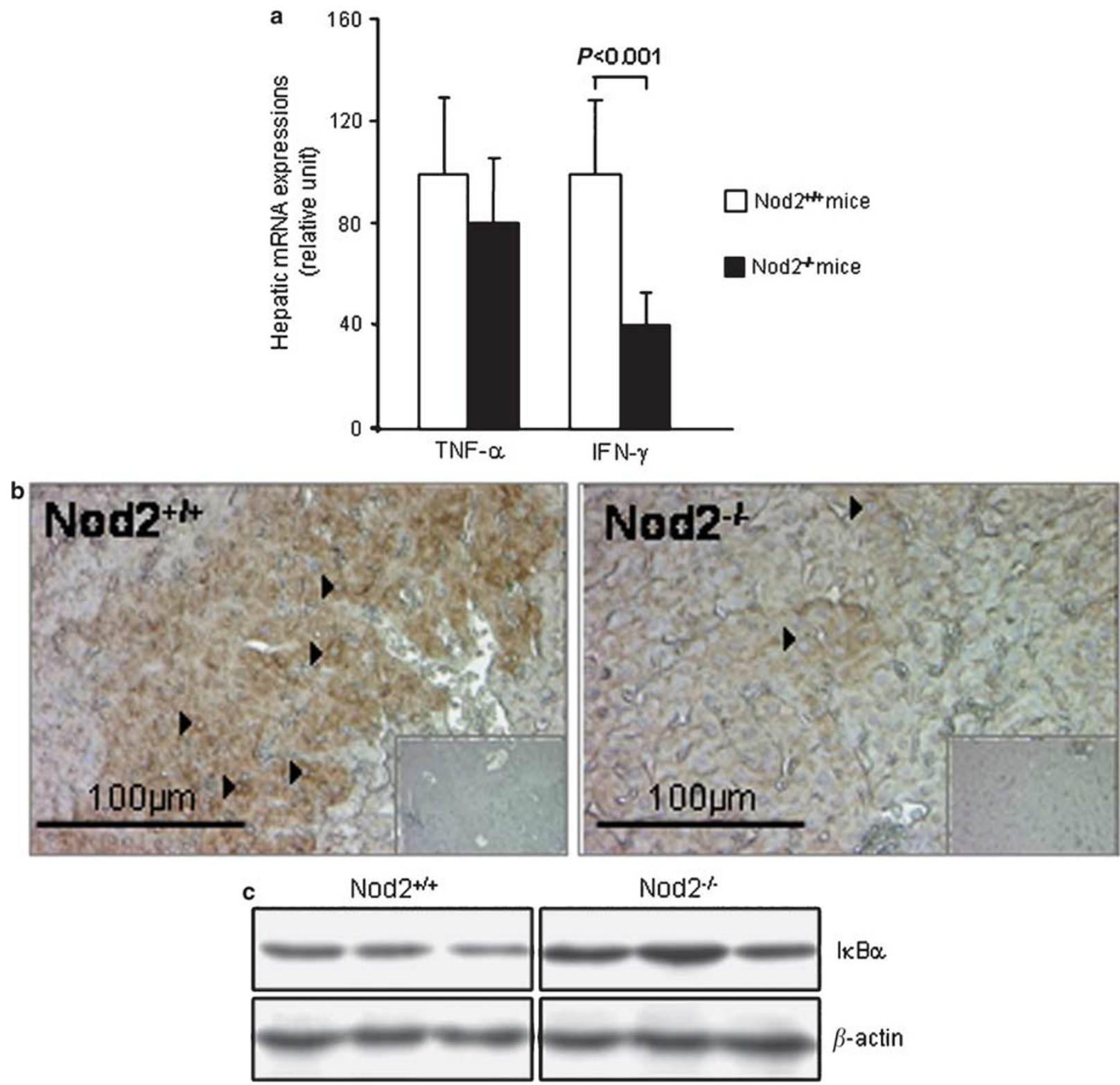

Figure 3 Limited inflammatory mediators in livers of ConA-treated Nod2 ${ }^{-/-}$mice. (a) Hepatic expression of cytokines after ConA challenge. A significant decrease in IFN- $\gamma$ mRNA levels was observed in Nod2 ${ }^{-1-}$ mice $(n=27)$ compared with Nod2 $2^{+1+}(n=24)$ mice. Results are expressed as mean \pm s.e.m. Statistical significances are indicated. (b) Representative IFN- $\gamma$ staining on livers of ConA-treated Nod2 $2^{+/+}(n=10)$ and Nod $2^{-/-}$mice $(n=10)$. Brown IFN- $\gamma$ staining was mainly located in injured areas surrounding infiltrating lymphocytes (arrowheads) in Nod $2^{+/+}$mice. IFN- $\gamma$ expression was lower in livers taken from $\mathrm{Nod}_{2}{ }^{-1-}$ mice than in those from Nod2 ${ }^{+/+}$mice. Negative controls are shown in insert in the lower right-hand corner. (c) Western blot incubated with antibody directed against $\mathrm{I} \kappa \mathrm{B} \alpha$, showing weaker degradation of the inhibitor of NF- $\kappa \mathrm{B}$ on liver protein extracts from Nod $2^{-/-} \operatorname{compared}$ to Nod $2^{+/+}$mice. The blot shows representative (three out of 10) mice of each genotype.

Figure 4 Muramyl dipeptide administration in mice worsens ConA-induced hepatitis. C57BL/6 mice that received i.p. either saline (white bars) or $100 \mathrm{mg} / \mathrm{kg}$ of MDP (black bars) were injected i.v. with $10 \mathrm{mg} / \mathrm{kg}$ of ConA (ConA) or with saline (Ctrl). (a) Mice that received both ConA and MDP showed a significant increase in their serum liver enzyme levels compared with mice that received ConA alone. (b) Representative H\&E section magnification $\times 50$ (left panel) and $\times 200$ (right panel) of livers from ConA (upper panel) and ConA + MDP mice (lower panel). Histological analysis showed more necrosis (arrows) in mice that received MDP $($ ConA + MDP) than in mice that received saline (ConA). (c) Hepatic expression of cytokines $24 \mathrm{~h}$ after ConA challenge. Injection of MDP in ConA-treated-mice $\left(\right.$ ConA + MDP) leads to a significant increase in TNF- $\alpha$, IFN- $\gamma$ and NOD2 mRNA levels compared with injection of saline (ConA). (d) Eight-week-old Nod2 ${ }^{+1+}$ $(n=8)$ and $\operatorname{Nod}^{-1-}$ mice $(n=8)$ were injected with $10 \mathrm{mg} / \mathrm{ml}$ of ConA in two independent experiments. Plasma was collected and livers were harvested $24 \mathrm{~h}$ after ConA injection. Aspartate aminotransferase (AST, left panel), alanine transaminase (ALT, right panel) were measured in the plasma of mice using the standard photometric method (Hitashi 747 analyzer). Four mice of each genotype received an i.p. injection of saline (saline, white bars) and four other mice received i.p. $100 \mathrm{mg} / \mathrm{kg}$ of MDP (MDP, black bars). Results are expressed as mean \pm s.e.m. Statistical significances are indicated. NS: not significant. 
received only saline and five mice received saline instead of ConA and MDP. Blood was collected and livers were harvested $24 \mathrm{~h}$ after ConA injection. ALT and AST were measured in the sera of mice using the standard photometric method (Hitashi 747 analyzer). One part of the liver was fixed in paraformaldehyde $4 \%$ and paraffin-embedded for histological analysis and another part was frozen for RNA studies.
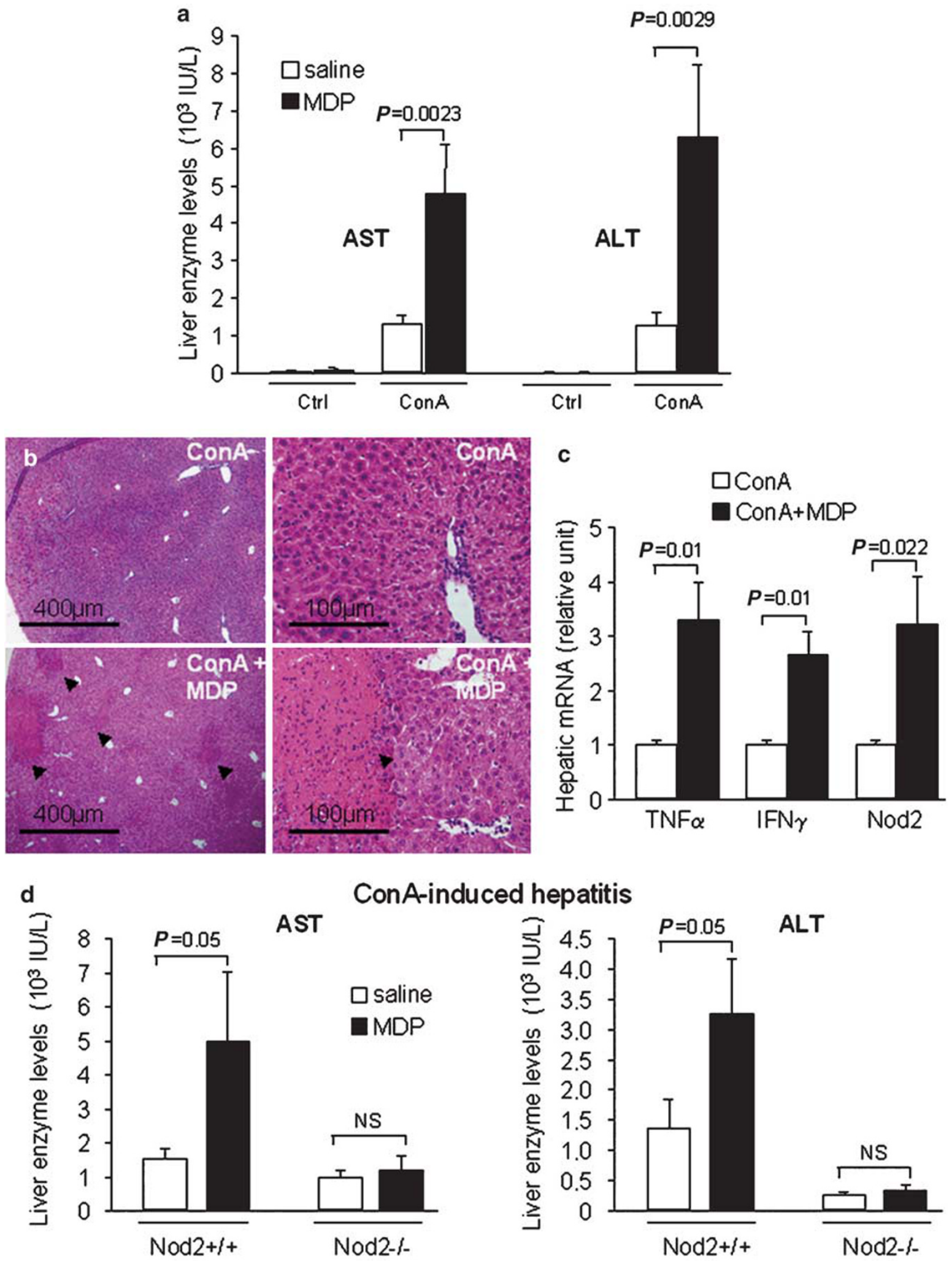


\section{Role of MDP in IFN- $\gamma$ Production in Hepatic Cells and Splenocytes}

Human PBMC and hepatocytes were isolated and cultured. These cells were pretreated or not for $24 \mathrm{~h}$ with TNF- $\alpha$ $(50 \mathrm{ng} / \mathrm{ml})$ and IFN- $\gamma(100 \mathrm{ng} / \mathrm{ml})$ and then exposed to MDP $(1 \mu \mathrm{g} / \mathrm{ml})$ for 6 or $9 \mathrm{~h}$. Two independent experiments were performed in triplicate. Splenocytes from mice were isolated by disruption of spleen in PBS containing bovine serum albumin and EDTA. After washing, cells were counted and plated in a six-well plate using RPMI medium. Splenocytes were cultured for $16 \mathrm{~h}$ with or without $1 \mu \mathrm{g} / \mathrm{ml}$ of MDP and harvested for IFN $\gamma$ mRNA quantification by real-time PCR.

\section{Statistics}

Data were expressed as mean \pm s.e.m. or mean \pm s.d. Statistical comparisons were performed using the Mann-Whitney test. A $P$-value $<0.05$ was considered as significant.

\section{RESULTS \\ NOD2 Expression is Upregulated During Liver Injury in Mice and Humans}

To investigate pathophysiological regulation of NOD2, we quantified TNF- $\alpha$, IFN- $\gamma$ and NOD2 during a full time course of gene expression in response to LPS and ConA in mice. After intraperitoneal injection of LPS, livers displayed an expected increase in TNF- $\alpha$ mRNA, with a peak at $1 \mathrm{~h}$ and then a decrease, whereas IFN- $\gamma$ mRNA peaked at $4 \mathrm{~h}$ (Figure 1a). NOD2 mRNA kinetics showed sustained increased expression, with a biphasic curve containing a first peak at $1 \mathrm{~h}$ which paralleled TNF- $\alpha$, and a second, weaker peak at $12 \mathrm{~h}$ (Figure 1a).

In ConA-induced hepatitis in mice, TNF- $\alpha$ and IFN- $\gamma$ mRNA levels peaked at 4 and $2 \mathrm{~h}$ respectively (Figure $1 \mathrm{~b}$ ). NOD2 mRNA peaked at $2 \mathrm{~h}$ and remained stable from 2 to $12 \mathrm{~h}$ and then decreased progressively (Figure $1 \mathrm{~b}$ ). Immunohistochemical results also argued in favor of upregulation of NOD2 protein expression in ConA-induced hepatitis (Figure 1c). Moreover, in the human hepatocyte cell line HepG2, NOD2 mRNA expression was upregulated by TNF- $\alpha$ and IFN- $\gamma$ (Supplementary Figure 1). This upregulation of NOD2 was synergized after stimulation with both TNF- $\alpha$ and IFN- $\gamma$ (Supplementary Figure 1).

In human autoimmune hepatitis, which is a typical liver disease mediated by lymphocytes and driven by proinflammatory cytokines such as IFN $-\gamma$, we observed significant hepatic induction of NOD2, TNF- $\alpha$ and IFN- $\gamma$ expression compared to control patients (Figure 1d).

\section{Mice Lacking Nod2 were Protected from ConA-Induced Hepatitis}

To further characterize the pathophysiological role of NOD2 in an experimental model of hepatitis, Nod2 $2^{-1-}$ mice were challenged with ConA. Twenty-four hours after hepatitis induction, Nod $2^{-1-}$ mice disclosed 86,91 and $77 \%$ decreases in AST, ALT and LDH levels, respectively, compared to their wild-type littermates (Figure 2a). Livers of ConA-treated wild-type mice showed diffuse necrosis in association with infiltration of mononuclear cells (Figure 2b). In contrast, morphological alterations were milder, with only slight focal injury, in livers of ConA-injected $\mathrm{Nod} 2^{-/-}$mice. Furthermore, objective quantification of the necrotic surface by image analysis showed decrease in damaged areas in Nod2 ${ }^{-1-}$ livers compared with Nod $2^{+/+}$livers (Figure 2c, 3 vs $13 \%$ respectively, $P<0.001$ ).

We analyzed the role of NOD2 during apoptosis induction in hepatocytes. In vivo, quantification of TUNEL-positive cells showed a decrease in hepatocyte apoptosis in Nod2 ${ }^{-1-}$ livers compared with Nod2 ${ }^{+/+}$livers (Figure 2d, $15.1 \pm 6.4$ vs $101.6 \pm 23, P<0.001)$.

In addition, we examined hepatic expression of different cytokine mRNA levels in livers of Nod2 $2^{+1+}$ and $\operatorname{Nod} 2^{-1-}$ ConA-injected mice. Significant reductions in IFN- $\gamma$, mRNA levels $(60 \%)$ were observed in $\mathrm{Nod} 2^{-1-}$ mice compared to their wild-type littermates (Figure 3a, $P<0.001$ ). At the protein level, immunostaining of IFN $\gamma$ was lower in livers taken from $\mathrm{Nod} 2^{-1-}$ mice than in those from Nod2 $2^{+1+}$ mice. In Nod $2^{+I+}$ mice (Figure 3 b, left panel), IFN $\gamma$ staining was mainly localized in injured areas surrounding infiltrating lymphocytes. In terms of mechanisms, $8 \mathrm{~h}$ after ConA injection, the livers of Nod $2^{-/-}$knockout mice displayed a $30 \%$ decrease in NF- $\kappa$ B activity compared to livers from wild-type mice (Figure 3c).

Taken together, these data suggest that $\mathrm{Nod}_{2} 2^{-1-}$ mice are resistant to ConA-induced hepatitis, and they support the role of NOD2 in regulation of hepatic injury, through IFN- $\gamma$ production by immune cells.

\section{MDP Exacerbates ConA-Induced Liver Injury in Mice}

To confirm that NOD2 regulates liver injury in a liganddependent manner, we showed that i.p. injection of MDP exacerbates ConA-induced liver injury, as indicated by: (a) a significant increase in AST/ALT (3.6-fold and 5-fold respectively, Figure 4a) and; (b) enlarged areas of necrosis and inflammation in livers compared to saline-treated mice (Figure $4 \mathrm{~b})$; (c) increased levels of inflammatory cytokines TNF- $\alpha$ and IFN- $\gamma$ (3.2-fold and 2.8-fold respectively, Figure 4c). In addition, NOD2 liver mRNA levels were induced in mice after i.p. injection of MDP (3.4-fold, Figure 4c). As expected, MDP alone did not induce significant liver injury in wild-type mice according to AST/ALT levels (Figure 4a). Moreover, MDP did not increase AST/ALT levels in liver of $\mathrm{Nod} 2^{-1-}$ mice, contrary to what is observed in Nod2 $2^{+1+}$ mice (Figure $4 \mathrm{~d}$ ).

\section{Cellular Distribution and Role of NOD2 in IFN- $\gamma$ Production}

To determine the cellular targets of MDP in promoting liver injury, we investigated NOD2 expression in different cell types present in the liver. Using real-time PCR, we showed that NOD2 expression was present in isolated human hepa- 


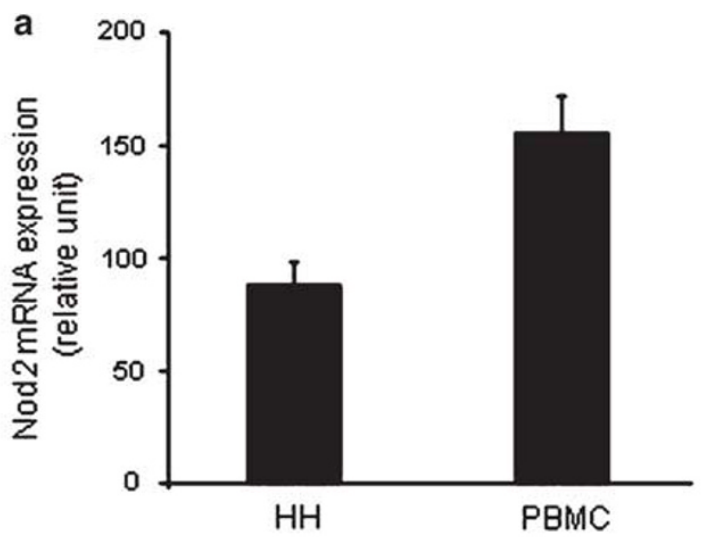

b

Nod2

$\operatorname{CD68}$
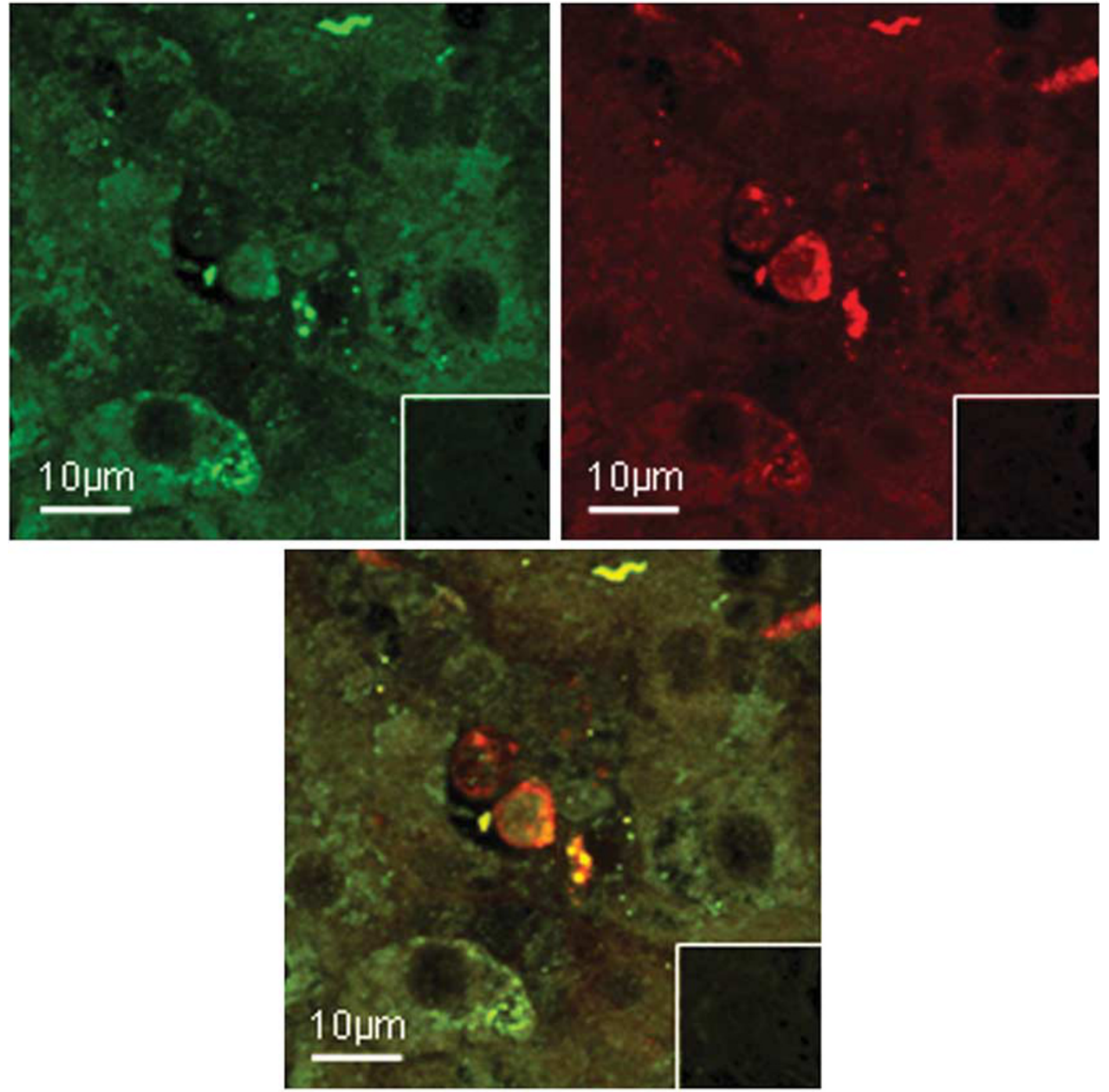

Merge

Figure 5 Cellular distribution of NOD2 in liver. (a) Determination of Nod2 mRNA expression by real-time PCR in human isolated hepatocytes and immune mononuclear cells (PBMC). Quantification was performed on five samples of each cell type. Results are expressed as mean \pm s.d. (b) Representative NOD2 staining in both liver mononuclear cells (eg Kupffer cells) and steady-state hepatocytes. Human liver was double-stained with antibodies directed against NOD2 and CD68 (magnification $\times$ 630). The anti-NOD2 antibody revealed specific green staining (Nod2: left panel) in hepatocytes and in liver mononuclear cells. The anti-CD68 antibody revealed specific red staining only in Kupffer cells and lymphocytes (CD68: right panel). Using confocal microscopy, superimposition of the two stainings gave yellow fluorescence in liver mononuclear cells (merge: lower panel). Negative controls were put in insert in the lower right-hand corner. 
tocytes and at comparable levels in immune mononuclear cells such as PBMC (Figure 5a). Confocal microscopy using an antibody directed against NOD2 and an antibody directed against CD68 showed that liver mononuclear cells as well as hepatocytes expressed NOD2 (Figure 5b).

To explore the role of NOD2 in immune cells, we demonstrated that MDP significantly induced IFN- $\gamma$ production by human PBMC after 6 and $9 \mathrm{~h}$ of stimulation with TNF- $\alpha$ and IFN- $\gamma$ (Figure 6a, $P=0.05$ ). To reinforce the ability of MDP to stimulate lymphocytes, one of the main cells involved in ConA-induced liver injury, we also showed that NOD2 activation upregulated IFN- $\gamma$ mRNA production in freshly isolated splenocytes stimulated with MDP (Figure $6 \mathrm{~b}, P=0.01$ ).

Finally, the effect of MDP on IFN- $\gamma$ production was explored in isolated human hepatocytes. In those cells pretreated with TNF- $\alpha$ and IFN- $\gamma$, MDP significantly induced IFN- $\gamma$ production after 6 and $9 \mathrm{~h}$ of stimulation $(P=0.028$ and 0.026 respectively Figure $6 \mathrm{c}$ ).
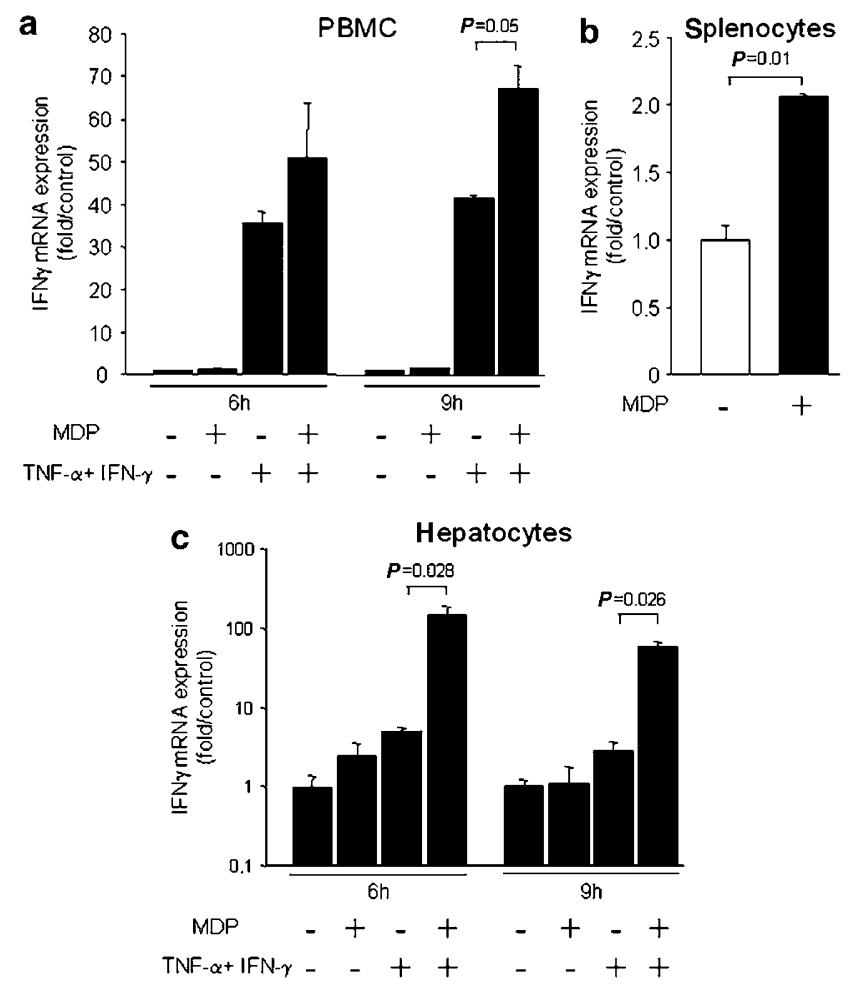

Figure 6 Role of MDP in IFN- $\gamma$ production in immune cells and hepatocytes. (a) IFN- $\gamma$ mRNA expression was quantified in human PBMC pretreated or not for $24 \mathrm{~h}$ with TNF- $\alpha$ and IFN- $\gamma$ and then exposed to MDP for 6 or $9 \mathrm{~h}$. (b) IFN- $\gamma$ mRNA expression was quantified in WT mice splenocytes exposed to MDP for $16 \mathrm{~h}$. (c) IFN- $\gamma$ mRNA expression was quantified in human isolated hepatocytes pretreated or not for $24 \mathrm{~h}$ with TNF- $\alpha$ and IFN- $\gamma$ and then exposed to MDP for 6 or $9 \mathrm{~h}$. Results are expressed as mean \pm s.e.m. of two experiments performed in triplicate. Statistical significances are indicated.

\section{DISCUSSION}

The recent discovery of receptors for bacterial compounds such as NOD2, which contribute to regulation of proinflammatory cytokine production in the digestive tract, ${ }^{17}$ constitutes an important challenge to our understanding of liver injury mechanisms. For the first time, we provide arguments that NOD2 is also implicated in liver injury.

The induction of NOD2 expression linked to cytokine production in different models of liver inflammation highlights similarities between intestinal cells and hepatocytes. This suggests common regulatory mechanisms involved in the innate immune response and its subsequent inflammation process in these two organs. Indeed, Rosenstiel et $a l^{14}$ had previously demonstrated that TNF- $\alpha$ and IFN- $\gamma$ synergistically cooperate to induce Nod2 expression in intestinal epithelial cells. We confirmed the same phenomenon at the cellular level using a hepatocyte cell line. Both LPS and ConA lead to activation of the NF- $\kappa$ B pathway which is involved in cytokine production. ${ }^{18,19} \mathrm{NF}-\kappa \mathrm{B}$ also induced NOD2 expression, which may explain at least in part the early peak following ConA and LPS challenge. ${ }^{11}$ The sustained increase in Nod2 expression may be associated with a regulatory loop, with early activation by NF- $\kappa \mathrm{B}$ followed by sustained stimulation, at least in part related to proinflammatory cytokines.

Direct evidence of the role of Nod2 in liver pathophysiology was provided by the resistance of $\mathrm{Nod} 2^{-I-}$ mice in ConA-induced hepatitis. It is well established that liver injury is associated with increased intestinal permeability, a phenomenon designated 'leaky gut', and which contributes at least in part to the observed rise in bacterial cell wall products in the portal tracts. ${ }^{1}$ This phenomenon has been demonstrated by the presence in the portal tract of entire bacterial pathogen products such as LPS at an early stage of liver injury. ${ }^{20,21}$ It is likely that small compounds such as MDP also cross the digestive barrier, but at an earlier stage. Nevertheless, the role of NOD2 acting through its ligand is confirmed by the exacerbation of ConA-induced liver injury after i.p. injection of MDP, the specific ligand of NOD2 and the absence of exacerbation of liver injury in $\mathrm{Nod}^{-1-}$ mice that received MDP.

The description of NOD2 expression by both immune cells and hepatocytes has created ambiguity in terms of which cell compartment is relevant for Nod2 expression with respect to liver injury. The model of ConA-induced hepatitis is mainly driven by immune cells such as lymphocytes, and involves different mechanisms such as apoptosis, necrosis and production of inflammatory cytokines. ${ }^{22,23}$ Immune cells display higher levels of Nod2 than hepatocytes and are usually the main source of IFN- $\gamma$ during liver injury. ${ }^{24}$ IFN- $\gamma$ together with other mediators are responsible for hepatocyte cell death. ${ }^{25,26}$ Our hypothesis is that Nod2 effects occur both in hepatocyte and immune cell compartments, with a probable major impact upon immune cells. The demonstration of the contribution of each compartment requires future studies 
using bone marrow reconstitution in which $\mathrm{Nod} 2^{-1-}$ bone marrow is deposited in wild-type mice, and using Nod2-specific deletion in hepatocyte compartments (AlbCre $\times \operatorname{Nod} 2^{\text {flox/flox }}$ mice) .

An intriguing aspect of our study lies in the fact that Nod2, a sensor of PAMPs mainly implicated in innate immunity, drives liver injury related to immune cells involved in adaptive immunity. Such a role for Nod2 also exists in inflammatory bowel disease, ${ }^{10}$ but has not been shown for other receptors of PAMPs such as TLR4 and CD14. Therefore, targeting of specific PAMPs might constitute an interesting approach depending on the potential mechanisms of liver injury. NOD2 antagonists might constitute potential candidates for limiting liver injury related to lymphocyte activation.

In conclusion, we provide the first evidence that NOD2 is a critical regulator of liver injury. The present study adds to our understanding of the pathogenesis of hepatic inflammation and rationalizes the performing of additional studies aimed at exploring this potential new target for treatment of liver injury.

Supplementary Information accompanies the paper on the Laboratory Investigation website (http://www.laboratoryinvestigation.org)

\section{ACKNOWLEDGEMENT}

We thank Monique Dussaillant, Leticia Carneiro, Hubert Louis, Emmanuelle Leteurtre and Candice Delaroche for excellent technical and intellectual assistance. We also thank Olivier Le Moine, Thierry Gustot, Christophe Moreno and Arnaud Lemmers for their critical reading of the paper. Our work was supported by French grants from the Arcir ('Conseil regional Nord Pas-de-Calais'), IREB (Institut de Recherches scientifiques sur les Boissons, Paris, France), INSERM ATC Alcool, ANR Physio 'LIFR-PP', the University of Lyon and the Institut Universitaire de France.

1. Inamura $T$, Miura $S$, Tsuzuki $Y$, et al. Alteration of intestinal intraepithelial lymphocytes and increased bacterial translocation in a murine model of cirrhosis. Immunol Lett 2003;90:3-11.

2. Girardin SE, Travassos $\mathrm{LH}$, Herve $\mathrm{M}$, et al. Peptidoglycan molecular requirements allowing detection by Nod1 and Nod2. J Biol Chem 2003;278:41702-41708.

3. Inohara N, Ogura $\mathrm{Y}$, Fontalba $\mathrm{A}$, et al. Host recognition of bacterial muramyl dipeptide mediated through NOD2. Implications for Crohn's disease. J Biol Chem 2003;278:5509-5512.

4. Maeda S, Hsu LC, Liu H, et al. Nod2 mutation in Crohn's disease potentiates NF-kappaB activity and IL-1beta processing. Science 2005;307:734-738.

5. Lala S, Ogura Y, Osborne C, et al. Crohn's disease and the NOD2 gene: a role for paneth cells. Gastroenterology 2003;125:47-57.

6. Ogura $Y$, Inohara N, Benito A, et al. Nod2, a Nod1/Apaf-1 family member that is restricted to monocytes and activates NF-kappaB. J Biol Chem 2001;276:4812-4818.
7. Ogura $Y$, Lala $S$, Xin W et al. Expression of NOD2 in Paneth cells: a possible link to Crohn's ileitis. Gut 2003;52:1591-1597.

8. Chamaillard $M$, Hashimoto $M$, Horie $Y$, et al. An essential role for NOD1 in host recognition of bacterial peptidoglycan containing diaminopimelic acid. Nat Immunol 2003;4:702-707.

9. Girardin SE, Boneca IG, Viala J, et al. Nod2 is a general sensor of peptidoglycan through muramyl dipeptide (MDP) detection. J Biol Chem 2003;278:8869-8872.

10. Kobayashi KS, Chamaillard M, Ogura $Y$, et al. Nod2-dependent regulation of innate and adaptive immunity in the intestinal tract. Science 2005;307:731-734.

11. Gutierrez O, Pipaon C, Inohara N, et al. Induction of Nod2 in myelomonocytic and intestinal epithelial cells via nuclear factorkappa B activation. J Biol Chem 2002;277:41701-41705.

12. Reid LM, Jefferson DM. Culturing hepatocytes and other differentiated cells. Hepatology 1984;4:548-559.

13. Bieche I, Onody P, Laurendeau I, et al. Real-time reverse transcriptionPCR assay for future management of ERBB2-based clinical applications. Clin Chem 1999;45(Part 1):1148-1156.

14. Rosenstiel $\mathrm{P}$, Fantini M, Brautigam K, et al. TNF-alpha and IFN-gamma regulate the expression of the NOD2 (CARD15) gene in human intestinal epithelial cells. Gastroenterology 2003;124:1001-1009.

15. Ogura $\mathrm{Y}$, Bonen DK, Inohara N, et al. A frameshift mutation in NOD2 associated with susceptibility to Crohn's disease. Nature 2001;411: 603-606.

16. Barreau F, Meinzer U, Chareyre F, et al. CARD15/NOD2 is required for Peyer's patches homeostasis in mice. PLoS ONE 2007;2:e523.

17. Strober W, Murray PJ, Kitani A, et al. Signalling pathways and molecular interactions of NOD1 and NOD2. Nat Rev 2006;6:9-20.

18. Ogushi I, limuro $Y$, Seki $E$, et al. Nuclear factor kappa B decoy oligodeoxynucleotides prevent endotoxin-induced fatal liver failure in a murine model. Hepatology 2003;38:335-344.

19. Trautwein C, Rakemann T, Brenner DA, et al. Concanavalin A-induced liver cell damage: activation of intracellular pathways triggered by tumor necrosis factor in mice. Gastroenterology 1998;114: 1035-1045.

20. Lumsden $A B$, Henderson JM, Kutner MH. Endotoxin levels measured by a chromogenic assay in portal, hepatic and peripheral venous blood in patients with cirrhosis. Hepatology 1988;8:232-236.

21. Mathurin P, Deng QG, Keshavarzian A, et al. Exacerbation of alcoholic liver injury by enteral endotoxin in rats. Hepatology 2000;32:10081017.

22. Kusters $S$, Gantner F, Kunstle $G$, et al. Interferon gamma plays a critical role in T cell-dependent liver injury in mice initiated by concanavalin $A$. Gastroenterology 1996;111:462-471.

23. Schumann J, Wolf $D$, Pahl A, et al. Importance of Kupffer cells for T-cell-dependent liver injury in mice. Am J Pathol 2000;157: 1671-1683.

24. Nicoletti $F$, Zaccone $P$, Xiang $M$, et al. Essential pathogenetic role for interferon (IFN-) $\gamma$ in concanavalin A-induced T cell-dependent hepatitis: exacerbation by exogenous IFN- $\gamma$ and prevention by IFN- $\gamma$ receptor-immunoglobulin fusion protein. Cytokine 2000;12: 315-323.

25. Guy CS, Wang J, Michalak TI. Hepatocytes as cytotoxic effector cells can induce cell death by CD95 ligand-mediated pathway. Hepatology 2006;43:1231-1240.

26. Tagawa Y, Sekikawa K, Iwakura Y. Suppression of concanavalin A-induced hepatitis in IFN-gamma(-/-) mice, but not in TNFalpha $(-/-)$ mice: role for IFN- $\gamma$ in activating apoptosis of hepatocytes. J Immunol 1997;159:1418-1428. 